\title{
Features of a Health-Oriented Education Program during Daily Commutes: A Qualitative Study
}

\author{
Ali Ramezankhani ${ }^{1}$, Akbar Babaei Heydarabadi ${ }^{2}$, Mohtasham Ghaffari ${ }^{3,4}$, Yadollah Mehrabi ${ }^{5}$, Sadegh Kazemi ${ }^{6}$
}

${ }^{1}$ Professor, Department of Public Health, School of Public Health, Shahid Beheshti University of Medical Sciences, Tehran, Iran

${ }^{2}$ Department of Public Health, School of Public Health, Student's Research Committee, Shahid Beheshti University of Medical Sciences, Tehran, Iran

${ }^{3}$ Environmental and Occupational Hazards Control Research Center, Shahid Beheshti University of Medical Sciences, Tehran, Iran

${ }^{4}$ Associate Professor, Department of Public Health, School of Public Health, Shahid Beheshti University of Medical Sciences, Tehran, Iran

${ }^{5}$ Professor, Department of Epidemiology, School of Public Health, Shahid Beheshti University of Medical Sciences, Tehran, Iran

${ }^{6}$ Master of Environmental Haelth, Red Crescent Society of Bavanat City, Fars, Iran

\section{Type of article: Original}

\begin{abstract}
Introduction: Today, despite scientific advances, many people spend more time and distance between home and their workplaces because of various economic and population reasons. The aim of this study was to identify features of an appropriate health education program during commutes for factory staff at Ardakan county (Yazd province, Iran).

Methods: This qualitative study was conducted via the phenomenological method in 2014. The population of this study was members of the staff of Ardakan Steel Company. Nineteen specialists and 11 members of the factory's staff were invited to participate in the study, and data were collected using semi-structured interviews. The interviews took 20 to 40 minutes, and their content was analyzed using content analysis.

Results: Extraction of codes and themes and their placement in this study showed that an educational program during commutes should have nine features to have the desired effectiveness, i.e., the program must be audienceoriented, repeatable, participatory, technology-based, combinational, supportive, and motivational and interesting. Also, the program should have environmental and organizational support, and it must be evaluated for its effectiveness.

Conclusion: Considering appropriate features of a health education program in educational situations, especially interventions related to daily commutes, is very important because the effectiveness of such health-oriented educational programs must be ensured.

Keywords: Features; Educational program; Commutes; Staff
\end{abstract}

\section{Introduction}

Commuting is travel that occurs periodically between one's place of residence and workplace. It also could involve study that encompasses daily trips that people must make via planes, trains, buses, public transportation, private car, or bicycle (1-3). Currently, despite numerous advances, many people spend more time and distance between home and work. However, until the 1800 s, most people arrived at work by walking less than an hour $(4,5)$. In a study by Rivera et al., average daily commutes of people in Germany, the U.S., and India per week were reported to be 11, 12, and 20 hours, respectively (6). In addition, in a study by Luiza et al., people in Brazil take 45 minutes, on average, to travel one way between their home and their place of work (7). In Queensland, the average distance and

\section{Corresponding author:}

Akbar Babaei Heydarabadi, Department of Public Health, School of Health, Student's Research Committee, Shahid Beheshti University of Medical Sciences, Tehran, Iran. Tel: +98.6133757341, E-mail: babaei.8946@gmail.com Received: December 12, 2015, Accepted: February 29, 2016, Published: June 2016 iThenticate screening: February 29, 2016, English editing: May 03, 2016, Quality control: June 02, 2016

(c) 2016 The Authors. This is an open access article under the terms of the Creative Commons Attribution-NonCommercialNoDerivs License, which permits use and distribution in any medium, provided the original work is properly cited, the use is non-commercial and no modifications or adaptations are made. 
time spent were $20 \mathrm{~km}$ and 50 minutes, respectively (8). In Tehran, people waste 12 million hours per day and 360 million hours per month in traffic jams (9). Based on this information, it is apparent that people large amounts of time just to get to their workplaces (6), and the staff members of factories are no exception. Therefore, considering this huge resource (i.e., time spent) and determining ways to optimize its use to promote people's health seems like a reasonable thing to do (10). A health program is, in fact, a general plan for activities that enhance health, and it refers to a series of services and activities that are designed, implemented, and evaluated to resolve one or more health-related problems $(11,12)$. In planning such a program, health needs, as well as objectives and educational content, are identified and prepared, and, then, educational methods and instruments are specified, and methods for evaluating the benefits that accrue to the learners are evaluated and specified (12). The goals of any health program should include reform of the healthcare delivery pattern, accelerating the creation of new health services, strengthening available services and reforming the methods of using them, removing unnecessary programs, promoting the quality of healthcare, making better use of manpower, and creating effective instructional resources $(13,14)$. Learning method and style are the main processes in an educational program, and these factors affect both teaching and learning. Identifying and explaining the factors that contribute to learning are among the main categories emphasized by experts $(15,16)$. Identifying the features and effective factors in any educational program (17) can be used to organize the educational environment, the quality of teacher's interactions, and the quality of teaching and learning the intended content (18). This information can increase the effectiveness of educational interventions by enhancing the learners' perceptions of realities and environmental conditions $(15,19)$. In many cases, employees prevent implementation of health-oriented educational programs in the workplace, and, during the work hours, the importance of daily commutes becomes prevalent when most people spend a significant amount of their time in this area and the necessity to consider these spent hours to promote health level of staff becomes more prevalent (10). Accordingly, conditions and features of implementing a health education program during commuting to work is different from conditions of implementing such a program in other settings, and the features that are required to make the program absolutely effective in assuring the efficiency and effectiveness of such a program must be identified. Since no study has been conducted in Iran or in other nations on this issue to date, this study was conducted with the aim of explaining the features of an appropriate health education program during commuting for the staff members of the Ardakan factory.

\section{Material and Methods}

\subsection{Setting}

This qualitative study was conducted via the phenomenological method in 2014. The population of this study was the staff members of the Ardakan Steel Factory. The participants were invited to participate in the study using the purposive sampling method. To access (primary) data and experiments, we employed experts, experienced individuals, and stakeholders. The participants included specialists of the fields of health education and promotion, medical education, educational technology, educational management, philosophy of education, and educational sciences, as well as factory managers, factory staff, and shuttle drivers.

\subsection{Inclusion Criteria}

The inclusion criterion for staff and managers was at least one year of work history in the factory. For drivers, the inclusion criterion was at least one year of work history as a shuttle driver. For related experts, the criterion was a history of conducting at least three studies on education and the different methods used to address various issues. Data saturation was the measure of sample adequacy.

\subsection{Data Collection}

Data collection was conducted using semi-structured interviews. In this study, after identifying participants for interviews, required coordination was conducted in terms of the interview subject and the time and place of interview in such a way that interviews were conducted in favorable a place and time for the interviewees. The interviews lasted for 20 to 40 minutes. The data were collected by voice recording and taking notes, after which the data were used in the analysis phase. To ensure the accuracy of the written data, they were typed and matched with the recorded statements, and, as a result, some of the details were modified to accurately reflect exactly what had been said. In the interest of ethics, the audio files of the interviews were erased after their content had been transcribed.

\subsection{Guiding Questions for Interviews}

As mentioned earlier, the data were collected using semi-structured interviews and guiding questions. These questions included: 
1) What are the features of an educational method during commutes? What items should be considered?

2) What methods can be used for education during daily commutes?

3) What are the features of daily commutes of people?

4) What are the conditions of people during daily commutes?

5) What are conditions of daily commutes for factory staff of Ardakan county?

\subsection{Data Analysis}

The data were analyzed using the content analysis method that included three phases, i.e., open coding, determining categories, and abstraction. First, the contents of the interviews were reviewed by the author several times to obtain some perceptions of their concepts. Then, the author reviewed the data line by line and word by word to determine the main concepts in each line or paragraph and code them. Similar codes were categorized in the same class, and themes were identified.

\subsection{Validity and Reliability}

In qualitative studies, validity and reliability refer to accuracy and consistency of data that include credibility, transferability, dependability, and confirmability $(20,21)$. Validity is specified by prolonged engagement with participants, using an integrated method to collect data, member checking and peer debriefing $(22,23)$. In this study, the data were reviewed by some participants, and the authors checked their findings to ensure the correct selection of themes and compliance with what participants had stated. In the reporting phase, we attempted to present a complete report along with mentioning the words of some participants. In addition, external supervisors verified the author's findings by studying the paper and adequate data presented in the report.

\section{Results}

Extraction and placement of codes and themes in this study demonstrated that an educational program during daily commutes should possess some features to have the desired effectiveness, i.e., this program should be audienceoriented, repeatable, participatory, technology-based, combinational, supportive, motivating, and attractive with environmental and organizational support and the capability of being evaluated.

\subsection{Being Audience-oriented}

Being audience-oriented is one of those features emphasized extensively by specialists. In fact, the major theme and focus of an educational program should be audience-oriented. Identifying the members of the audience, their conditions, and their characteristics should be conducted correctly to be a base for the program. Considering the preparedness of learners, their conditions during commutes (e.g., asleep, awake, tired, fresh), considering the time of teaching learners, considering underlying factors (e.g., age, gender), principles of adult education, personal characteristics of individuals (e.g., being studious), considering psychological condition of people, their mental ability, considering their accent, norms, and language, as well as their characteristics in terms of cultural, economic, social, and political features are some examples of audience-orientation as the theme of the program. An expert in the philosophy of education once stated, "The main basis for each educational program is its audience, and we cannot plan without considering and identifying them." An expert in medical education stated, "Considering adult education principles is very important since your audience, i.e., your everything, is an adult."

\subsection{Repeatability}

This feature refers to the repeatability of the program at different times, i.e., to be able to repeat the presented message in an educational program in specified times to review and deepen them. Repeating the educational program can address audiences that have yet to be exposed to the program in addition to reviewing and deepening it. An expert in educational technology stated, "To teach about issues and problems that are important and recur in various intervals, it is required to repeat educational program several times for remembrance." An expert of educational sciences stated, "Humans are forgetful creatures, and those things will remain in their memories that are dealt with more. Certainly, this is the philosophy of repetition since we forget things easily." In this regard, a 28 year-old worker said, "People usually forget those things that are learnt once. But when they learn them and repeat them several times, they cannot be forgotten easily."

\subsection{Participatory}

Another feature of an educational program is being participatory, i.e., the program is prepared and implemented by the help and cooperation of the audience. Engagement of people in planning and implementation, cooperation and consultation with the audience, not presenting top to bottom education, using people's experiences and attracting 
active participation of people are some examples of participation that are very effective in the success and efficiency of a program. An expert on the philosophy of education stated, "If the audience does not have a sense of estrangement with the program and regards it as their own program and know that their views are included in program, they will do their best to implement the program well and achieve results, since program success is regarded as their own success." An expert in health education and promotion stated, "One of the major reasons of success in any educational program is that our audience is engaged in all phases of program as far as possible, whether in planning phase or even before that (needs assessment), or in implementation, evaluation and judgment phase." In addition, a 47-year-old worker said, "We, people, who are working here are more familiar with conditions here and we know things that can help you very much to prevent your program failure."

\subsection{Technology-based}

New educational technologies have assisted education in many cases. Employing and using various media and appropriate technology considering conditions, can pave the way for achieving educational objectives. An expert of educational technology stated, "Today's scientific world is changing, transforming and developing at an unthinkable speed. Every day we encounter new educational software. We shouldn't stay behind technology and we should become familiar with new and updated technologies as far as possible and use those that are more useful for us." An expert of medical education stated, "There are lots of opportunities, facilities and new technologies that can be used today for teaching. Now you see what uproar is made by these mobile-based or Internet-based social groups. They share films and images around the world easily in the blink of an eye."

\subsection{Combinational}

It refers to using several educational methods proportional to the tastes and personalities of the individuals in an educational program. Employing several methods based on data, having a selective view, variability of methods in intervals, and not using a fixed method in the long run can assist educational programs in achieving their objectives and being successful. A health education and promotion expert stated, "In an educational program you should have optional views to allow people to have the power of selection. Maybe someone likes to read printed material while someone else prefers more to listen and see materials." A thirty-year-old worker said, "If they talk about something first and print a summary of that or text it for us, they will stay longer in our memory."

\subsection{Supportive}

An educational program during commutes should be complementary in some cases and play a supporting role. It means that, when an educational program is implemented on a special subject for the staff in the workplace by using a supportive educational program, it should be attempted to cover those materials that require repetition or emphasis during commutes. Initiating education from the workplace and continuing it in the shuttle along with considering a reminder on the way back could be helpful. A medical education expert stated, "Educational program initiated in the workplace can be continued during commutes and present supportive materials."

\subsection{Motivating and attractive}

Creating required incentives for the audience to participate in implementing the program and optimizing its use are the features of a successful educational program. Encouraging, giving rewards, gifts along with messages, presenting material and moral incentives, and a certificate by the factory can create motivation. The educational program should be designed in such a way to attract the audience's attention and bring organizational benefits along with educational achievements. For example, at the end of an educational course, a certificate could be awarded that is also useful for promotions. An expert of educational sciences stated, "The audience could be attracted by giving a certificate or other rewards to attract them to educational program and make the best use of it." An expert of philosophy of education mentioned "Knowing the philosophy of your educational program by the audience to know why they should participate such a program and what the use of learning those materials is, can affect their conscious and active participation in the program. Here, moral and material incentives are also very helpful." A 36year-old driver said, "If people know that they will be tested after implementation of educational program and top learners are rewarded, they will take it seriously."

\subsection{Environmental and Organizational Support}

Supporting an educational program and its providing team by an organization can greatly help success of the program and facilitate its implementation. An expert of educational technology mentioned, "Organizational support is a requirement to wrap up an educational program and if an organization is not very successful in this regard and it does not support you, it means that either your program is weak or you have not justified organization well." An 
expert of health education and promotion said, "Attracting the support of organization is the key to enter it. In some cases you have to create some changes in the organization that require relevant license and the organization's support. The degree of a program's success is directly related to the amount of support." A 57-year-old CEO mentioned, "If your program has required justification and it can convince us, there is no problem and required coordination will be done for any cooperation that can help your program to be implemented according to what you have planned or facilities you require."

\subsection{Capability of Evaluation}

Some participants emphasized the capability of evaluation for any educational program. An educational program should be capable of being evaluated to identify its weak and strong points and take steps in line with removing or strengthening them. By evaluating the program, it can be realized whether the program should be stopped, continued, or modified. An expert of educational management mentioned, "To know how much you have approached your pre-determined objectives, you must have an evaluation program." An expert of educational technology said, "By accurate evaluation of an educational program, its weak points can be reduced and its strong points can be increased." An expert of medical education said, "Efficiency and effectiveness of a program can be realized by evaluation to see whether this program is applicable. That's the way this is realized."

\section{Discussion}

Education is an inevitable need of any organization to promote the capability of its staff, which can increase the productivity and competitive power of the organization (24). Continuous training of employees is an important way of increasing an organization's productivity (26). Factory staff members normally commute twice a day (morning and evening), 10 to 12 times a week, 44 to 52 times a month, 548 to 624 times a year, and about 16,440 to 18,720 times during a 30 -year period of work. At least half of this travel time potentially can be an educational opportunity (10). This study was conducted in 2014 with the aim of identifying the features of an appropriate educational program during daily commuting, and it identified 10 features of an educational program. Being audience-oriented is one of the features more emphasized by experts. In fact, the main theme and focus of an educational program should be audience-oriented. Identifying the audience, their conditions, and their characteristics should be conducted accurately and should be the foundation of the program. Considering preparedness of learners, their conditions during commutes (e.g., asleep, awake, tired, fresh), considering time of teaching learners, considering underlying factors (e.g., age, gender), principles of adult education, personal characteristics of individuals (for example being studious), considering psychological condition of people, their mental ability, considering their accent, norms and language, as well as their characteristics in terms of cultural, economic, social, and political features are some examples of audience-orientation as the theme of the program. Since educational interviews are audience-oriented, they can be one of the solutions of efficiency in an educational program (27). Based on the Merrill educational model, the first stage of educational planning is determining learners' characteristics as the theme of the program (28), and, therefore, educational activities should match the audience's needs $(29,30)$. This feature refers to repeatability of program in different times, i.e., it should be possible to repeat the presented message of an educational program at a specified time to review and deepen it. Repeating an educational program can reach the potential audience that was not exposed to the program in addition to reviewing and deepening it. Exercise and repetition have main roles in learning. According to experts, the effects of practicing and repetition along learning process and its different fields, especially in the psychosomatic field, are undeniable. Effective practicing and repeating have their own conditions and features. For instance, they should be regular, and the duration of the course should be appropriate (31). A repeated message stays in the memory longer. Therefore, repeating educational content in determined intervals significantly assists and deepens the learning process (28). Conscious and purposeful use of the repetition technique is effective on the audience's concentration on the main points. Repetition can be in the form of a simple remembrance or reviewing taught materials (32).

Another feature of an educational program is that it must be participatory. Engagement of beneficiaries in planning and implementation, cooperation and consultation with audience, not presenting top to bottom learning, using people's experiences, and attracting people's active participation are some examples of participation that are very effective in the success and efficiency of a program. Active participation of the audience in the learning process and encouraging the role of being an active learner nurture deep learning and increase self-direction and innovation capacity that consequently increases the self-confidence and success of the audience $(29,30)$. In a qualitative study, Merghati et al. discussed students' participation in educational planning and valuing their views as factors that affected the program's success (33). According to Shahavi et al. in a qualitative study of the phenomenological method, among the major weak points of clinical training were a lack of coordination of educational planning and 
neglecting the audience's views in planning (34). Furthermore, several studies have emphasized the determinant role of audience participation in different stages of the learning and teaching process (35-38). Educational planning with the participation of all practitioners can meet the educational needs of people and result in their satisfaction $(29,30$, 39). In many cases, media and educational aids have significantly assisted education. Employing and using different media and appropriate technology, considering conditions, paves the way to achieve educational objectives. Educational media are tools that can be used to present education to the learner, which naturally is regarded as part of the teaching process and educational technology, but not the whole of it. In educational programs, using appropriate media with regard to other factors can play a major role in more effective achievement of the intended objectives and facilitate the learning process (28). In various studies, the importance of accurate and appropriate use of media and educational aids to present better teaching to audiences is dealt with $(36,37,40)$ and not using them appropriately is regarded as a weak point of education (34). It refers to using several educational methods proportional to the tastes and characteristics of the people in an educational program. Using several methods based on information, having a selective view (having the right of selection), variability of methods in intervals, and not using a fixed method in the long run can assist the success of an educational program in achieving its intended objectives. Companionship of speech and image and their combinational use are effective in learning (28). Engagement of people through various methods (e.g., audio, listening, speech), considering available resources and facilities, simplifies successful implementation of an educational course (40). The variety of educational content is similar to the variety of educational objectives, which can be different for different educational objectives (28). According to Merrill, in the learning process, the "explaining and expanding presentation method," which is, in fact, supportive to all teaching methods, content is taught via one or more methods (28). Integrating numerous teaching methods and media assists them to compensate for their weaknesses and deficits in relation to the teaching process and complement each other's capacity (41). An educational program during commutes should be Complementary and play the supportive role in some cases. It means that when an educational program was implemented on a special subject in workplace for staff, by implementing a supportive educational program, it should be attempted to cover those materials that require repetition or are emphasized during commuting. Initiating teaching in the workplace and continuing it in the shuttle or putting a reminder on the way back can be helpful in this regard. Presenting a learning guide is part of the learning process that can be presented in different situations (28).

Creating sufficient motivation on the part of the audience to participate in the program's implementation and optimization of its use are some features of a successful educational program. Encouraging, giving rewards, gifts along with messages, presenting material and moral incentives, and a certificate by the factory can create motivation. An educational program should be designed in such a way to attract the audience's attention and bring organizational benefits as well as educational achievements for them. For example, at the end of an educational course, a certificate can be awarded that is useful for promotions. Attracting attention and creating motivation are primary requirements in the teaching process, and the effectiveness of other educational stages depends on them. Attracting learner's attention is the requirement of concentration and an introduction to learning that has a major role in directing the attention and the energy consumed by the learner (28). Encouraging and motivating the audience affects learning significantly $(33,42)$. And the greater the motivation is, the more adamantly and longer people will pursue their objectives (28). An organization's support of an educational program and the team that presents it can assist the success of program very much and facilitate its implementation. Conditions, facilities, and equipment in educational planning should provide a supporting environment for the audience in order to promote the quality of the learning opportunity $(34,37)$. In the constructivism approach, which is one of the approaches of educational planning, the educational situation and environment are of major importance in the audience's learning (43). A potential environment for learning assists learners' maintenance and attraction and stimulates their interest in learning (44). Some participants emphasized the capability of evaluation of the educational program. An educational program should be capable of being evaluated to identify its weak and strong points and to take steps to remove or strengthen them shortcomings. Educational evaluation refers to an orderly process to determine and specify learner's progress in achieving educational objectives (12). By evaluating the program, it can be realized whether the program should be stopped, continued, or modified. Evaluation is an integral part of the teaching-learning process that should be conducted along with education in a close, continuous relationship $(38,45)$. Considering what was mentioned earlier, health-oriented programs that are going to be implemented in this new setting, i.e., during daily commutes, should have the above-mentioned features for having higher efficiency and effectiveness and to be a more effective measure for optimized used of this time. One of the limitations of this study was the lack of easy access to some education experts. 


\section{Conclusions}

The findings of this study showed that a health educational program during daily commutes should be audienceoriented, participatory, technology-based, combinatory, supportive, motivating and attractive, with environmental and organizational support and capable of being evaluated. Since a huge amount of time is wasted during daily commutes, one of the ways of using this time is paying attention to educational issues, and this time can be used productively with appropriate planning to increase individuals' health status. Considering the features of an appropriate educational program in all conditions, especially in educational programs related to daily commutes, is of high importance because of the possibility of increasing the efficiency and effectiveness of health-oriented interventions more than ever. It is suggested that studies be designed, implemented, and evaluated in line with conducting health education interventions during people's daily commutes.

\section{Acknowledgments:}

This paper was extracted from a Ph.D. dissertation on health education and promotion, and, hereby, the authorities of the Steel Companies in Ardakan County who attended this study are greatly appreciated. This paper was approved by the Research Deputy of Shahid Beheshti University of Medical Sciences under the code of 1393-1-1321307 , and he and his staff also are appreciated.

\section{Conflict of Interest:}

There is no conflict of interest to be declared.

Authors' contributions:

All authors contributed to this project and article equally. All authors read and approved the final manuscript.

\section{References:}

1) Wikipedia. Commuting, From Wikipedia, the free encyclopedia, [Online]. [Cited 2013 Sept 28]; Available from: http://en.wikipedia.org/wiki/Commuting.

2) Shephard RJ. "Is active commuting the answer to population health?" Sports Medicine. 2008; 38(9): 751-8. doi: 10.2165/00007256-200838090-00004. doi: 10.2165/00007256-200838090-00004.

3) Oxford dictionary. Definition of commute in Oxford dictionary. [Online]. [Cited 2013 Sept 1]; Available from: http://www.oxforddictionaries.com/definition/english/commute.

4) Moss Ch. Smoothly from Harrow: A compendium for the london commuter, Blue Guides, 2013.

5) Bopp MJ, Kaczynski AT, Besenyi GM. Active commuting influences among adults. Prev Med. 2012; 54(4): 237-41. doi: 10.1016/j.ypmed.2012.01.016. PMID: 22327047.

6) Rivera MB, Henriksson G, Akerlund M. Getting there and back again. Commuting and ICT in six cities across the globe. Stockholm, 2012; 1-29.

7) Franco LPC, Campos VBG, Monteiro FB. A characterisation of commuter bicycle trips. Procedia Soc Behav Sci. 2014; 111: 1165-74. doi: 10.1016/j.sbspro.2014.01.151.

8) Department of Transport and Main Roads. Central Business District Travel: Travel in south-east Queensland May 2012.

9) Ghadermarzi H. Every month, 360 million hours are wasted in traffic in Tehran. [Online]. [Cited 2013 Sept 28]; Available from: http://ilna.ir/news/news.cfm?id=131332.

10) Babaei Heydarabadi A, Ramezankhani A, Ghaffari M, Mehrabi Y. Features of an appropriate method of health education during commutes: a qualitative study. Ind J Fund Appl Life Sci. 2015; 5(S2): 115-24.

11) Hatami H, Razavi SM, Eftekhar H, Majlesi F, Sayed Nozadi M, Parizadeh MJ. Text book of public health. Tehran, Arjmand, 2008.

12) Akbari M, Rafieifar, I Samir, Mohammadi N, Aghamollaei T, Aminshokravi F, et al. Health education curriculum (introduction to the basic concepts): Managers and employees of the health system. Tehran, Mehr Ravash, First edition, 2006.

13) Nekuei Moghaddam M, Beheshtifar M. Health services planning. Tabriz, Akhtar, 2005.

14) Green A. An introduction to health planning in developing countries. Oxford: Oxford University Press; 1999.

15) Karimi Moneghi H, Dabbaghi F, Oskouie S, Julkunen KV, Bionghi T. Teaching Styles in Clinical Nursing Education: A Qualitative study of Iranian nursing teachers' experiences. Nurse Educ Pract. 2010; 10(1): 812. doi: 10.1016/j.nepr.2009.01.016. PMID: 19251481.

16) Jannat Alipour Z, Navvabi N, Jahanshahi M. Evaluation of Nursing Students' Learning Styles Based on VARK Learning Pattern in Ramsar School of Nursing \& Midwifery. 2013; 1(2): 37-45. 
17) Ohrling K, Hallberg IR. Student nurses' lived experience of preceptorship. Part 2-the preceptor-preceptee relationship. Int J Nurs Stud. 2000; 37(1): 25-36. doi: 10.1016/S0020-7489(99)00055-3.

18) Gillespie M. Student-teacher connection in clinical nursing education. J Adv Nurs. 2002; 37(6): 566-76. doi: 10.1046/j.1365-2648.2002.02131.x. PMID: 11879421.

19) Yassini Ardekani S, Banaei Borujenei S, Mirzaei Alavijeh M, Motlagh ZF, Faryabi R. Learning styles and preferred teaching methods in students of Shahid Sadoughi University of Medical Sciences-Yazd. Journal of Medical Education and Development. 2013; 7(4): 63-72.

20) Braun V, Clarke V. Using thematic analysis in psychology. Qual Res Psychol. 2006; 3(2): 77-101. doi: 10.1191/1478088706qp063oa.

21) Salmani N, Abbaszadeh A, Rassouli M. Perceptions of mothers from barriers of nursing care satisfaction: a qualitative research. J Qual Res Health Sci. 2014; 3(1): 51-61.

22) Mehrdad N, Haghdost F, Seyed Fatemi NS, Ebrahimi H, Rezair M. Qualitative content analysis. Tehran, Iran: Boshra Publication; 2013. [In Persian].

23) Saffari M, Eftekhar H, Seyed Emami R, Mahmoodi M, Ahmadpour F, Shojaeizadeh D, et al. Qualitative research methods in: health education and promotion research methods. 1st Tehran: asaresobhan; 2009; PP: 232-3, 140-3, 231-49.

24) Hadavand S, Kashanchi AR. Effective Factors on Electronic Learning. Quarterly of Education Strategies in Medical Sciences. 2013; 6(2): 89-93.

25) Unneberg L. Grand designer for e-learning: Can e-learning make the grade for our biggest corporate? J Ind Commer Training. 2007; 39(4): 204-11. doi: 10.1108/00197850710755122.

26) Khoshneshin Z, Khoshnoudi Far M. The necessity of staff's needs assessment in e-based learning. Magazine of E-learning Distribution In academy (MEDIA). 2014; 5(3): 78-84.

27) Shamsi M, Neyestani H, Ebrahimipour H, Esmaeili H, Vafaei najjar A, Nosrati M. Using social marketing model to persuade the women to do mammography. SJSPH. 2014; 12(1): 85-96.

28) Fardanesh H. Theoretical foundations of educational technology. Tehran, Samt, edition 7, 2005: 17, 122-5, 133-5, 149, 189.

29) Rye KJ. Perceived benefits of the use of learning contracts to guide clinical education in respiratory care students. Respir Care. 2008; 53(11): 1475-81. PMID: 18957150.

30) Sajadi Hezaveh M, Boorim Nejad L. Learning Contract: A method of Teaching in nursing. Iranian Journal of Medical Education. 2012; 11(7): 696-700.

31) Shabani H. Educational skills. 1st. Tehran: Semat; 2008: 22.

32) Shojaeizadeh D, Shaahmadi F, Rohani H. Health Communication: Theory and practice. 1st. Tehran: Asaresobhan; 2014: 82, 94.

33) Merghati khoii E, Rimaz Sh, Zarei F, Dastoorpour M, Baiat AR. Exploring the teaching and learning approaches from the viewpoint of Postgraduate Students and their Lecturers. Journal of Health Education and Health Promotion. 2013; 1(3): 67-82.

34) Shahoei R, Hesami K, Zaheri F, Hashemi Nasab L. The experience of graduated midwifery students about clinical education: A phenomenological study. The Journal of Medical Education and Development. 2013; 8(1): 2-13.

35) Izadi A, Torabi M, Hasani P, Oshvandi K. Pathology of "clinical education" from perspective of nursing students: a qualitative content analysis. The Journal of Urmia Nursing and Midwifery Faculty. 2015; 13(1): 9-18.

36) Salehabadi S, Golafroz shahri M, Nasrollahi S, Akbarzadeh M, Mircholi N. Clinical education problems and ways of enhancing its quality from the perspective of clinical instructors and students of nursing and midwifery at Sabzevar University Medical Sciences in 2008. Journal of Sabzevar University Medical Sciences. 2014; 20(4): 539-46.

37) Delaram M, Aein F, Safdari F. The viewpoints of nursing and midwifery students about the problems of clinical education in Shahrekord. The Journal of Medical Education and Development. 2006; 1(1): 20-4.

38) Baharvand P, Nazer M. Assessment of medical students performance in Lorestan University of Medical Sciences with 360-degree method. Education Development Center Babol University of Medical Sciences. 2013; 1(1): 56-60.

39) Asadizaker M, Abedsaeedi Zh, Abedi HA. Development of clinical teaching process of the fundamentals of nursing with participatory approach: an action research. J Qual Res Health Sci. 2014; 3(2): 175-89.

40) Khoshneshin Z, Khoshnoudifar M. The necessity of staff's needs assessment in E-based learning. MEDIA. 2014; 5(3): 78-84. 
41) Asadi AH, Zarei F, Nasiri A, Moravveji S, Keykhani R, Tehrani H, et al. Digital media \& Health. 1st. Tehran: Asaresobhan; 2012: 15, 131.

42) Hanifi N, Parvizy S, Joolaee S. Motivational journey of Iranian bachelor of nursing students during clinical education: a grounded theory study. Nurs Health Sci. 2013; 15(3): 340-5. doi: 10.1111/nhs.12041, PMID: 23506351.

43) Fazeli AR, Karimi M. Teacher training students' experiences of instructional designing based on the constructivism approach. Research in Curriculum Planning. 2015; 12(18): 140-50.

44) Saffari M, Pakpour A, Sanaeinasab H. Educational technology in health field. 1st. Tehran: Asaresobhan; 2012: 53 .

45) Menna J, Petty M, Wheeler RP, Vang O. Evaluation of medical student professionalism: a practical approach. Medical Science Educators. IAMSE. 2005; 15(2): 45-8. 